had suffered from headaches, and generalised aches and pains. On examination both temporal arteries were thickened, nonpulsatile and tender. She was completely blind in the left eye with vision in the right eye diminished to hand movements. The right fundus showed a pale swollen disc and a few retinal haemorrhages, and the left optic disc looked atrophic. Investigations revealed $\mathrm{Hb}$ of $10 \mathrm{~g} / \mathrm{dl}$, erythrocyte sedimentation rate (ESR) $115 \mathrm{~mm} / \mathrm{h}$; liver function tests were markedly deranged with elevation in alkaline phosphatase to $3750 \mathrm{IU} / 1(\mathrm{n}=80-350), \gamma$ glutamyl transferase $(\gamma-\mathrm{GT})$ to $769 \mathrm{IU} / 1$ $(n=<55)$ and aspartate aminotransferase (AST) to $129 \mathrm{IU} / 1 \quad(\mathrm{n}=7-35)$, normal bilirubin, low albumin of $29 \mathrm{~g} / 1(\mathrm{n}=35-52)$ and total protein of $56 \mathrm{~g} / 1 \quad(n=63-80)$. HBsAg and anti-HBs (anti-HCV not available at the time) were negative and an autoimmune profile was normal. Ultrasound examination of the abdomen showed normal liver and biliary system. Occipital artery biopsy showed the classical features of giant cell arteritis.

She was initially treated with high-dose dexamethasone with improvement in the right eye vision from hand movements to $6 / 9$ $36 \mathrm{~h}$ later but she remained blind in the left eye. She was started on prednisolone $60 \mathrm{mg}$ daily and remained on a maintenance dose of 10-15 mg daily. Three months later there was improvement in the liver function tests. Liver biopsy performed at this stage showed nonspecific fatty changes and portal tract and intralobular infiltration with inflammatory cells and mild bile stasis in the biliary canaliculi.

There are several reports of mild to moderate hepatic dysfunction in association with polymyalgia rheumatica/temporal arteritis. ${ }^{1}$ The commonest abnormality is mild to moderate elevation of alkaline phosphatase with or without changes in the liver enzymes. Retention of bromsulphalein has been observed to be the common abnormality in some series and a striking correlation between the magnitude of the increase in alkaline phosphatase with ESR and bromsulphalein retention has been noted. ${ }^{2}$

Hypoalbuminaemia and increase in alpha1 and alpha- 2 globulins are frequently noted during the acute phase of this illness. Mild to moderate disturbance of liver enzymes and prolonged prothrombin time have also been

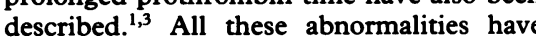
been shown to return promptly to normal following steroid therapy.

Histopathological studies of the liver biopsies from patients with polymyalgia rheumatica/temporal arteritis are limited. They are predominantly reported to be normal or to show nonspecific changes and occasionally presence of granulomas. ${ }^{1,2}$ Von Knorring and Wasastierna ${ }^{2}$ have demonstrated structural changes in the biliary canaliculi in the form of widening and irregularity of the canalicular wall. Recently, one of the present authors (KNA) has reported changes of ultrastructural injury to biliary canaliculi in a case of biopsy proven temporal arteritis. ${ }^{4}$ The pathogenesis and significance of these hepatic changes remains uncertain.

Clinically, our patient had a widespread arteritic process. It is likely that the hepatic arteries were involved in the generalised vacsulitic process, producing marked hepatic enzyme abnormalities which returned to normal over a period of six months on steroid therapy.

KESARAKODI N ACHAR RICHARD P ASHFIELD

West Dorset General Hospitals NHS Trust, Dorset County Hospital, Dorchester, Dorset DT1 1TS, UK

1 Holdstock G, Milward-Sadler GH, Wright $\mathbf{R}$. Hepatic changes in systemic disease. In: Wrigh R, Milward-Sadler GH, Alberti KGMM, Karran $S$, eds. Liver and biliary disease, 2nd edn. Bailliere Tindall-WB Saunders Company, 1985; pp 1033-76.

2 Von Knorring J, Wasastjerna C. Liver involvement inpolymyalgia rheumatica. Scand $\mathcal{f}$ Rent inpolymyalgia rheum

3 Dickson ER, Maladonado E, Sheps SG, Cain Dickson ER, Maladonado E, Sheps SG, Cain JA. Systemic giant cell-arteritis with polym
gia rheumatica. $₹ A M A$ 1973; 224: $1496-8$.

4 Achar KN, Al-Alousi SS, Patrick JP. Biliary ultrastructural changes in the liver in a case of giant cell arteritis. Br $\mathcal{f}$ Rheumatol 1994; 33 $161-4$.

\section{Attitudes of junior medical staff to requesting permission for autopsy}

Sir,

Hinchcliffe et al make some interesting observations in relation to the attitudes of junior medical staff towards autopsy requests and we believe that these issues merit further discussion. ${ }^{1}$ The recommendations of the joint working party of the Royal Colleges, which included the Royal College of Physicians of London, clearly state that the responsibility for obtaining consent for autopsies lies with the consultant in charge of the case. ${ }^{2}$ Whilst this responsibility may be delegated, this should be a positive act and appropriate training in how to request permission for autopsies is the proper duty of senior clinicians. Those individuals responsible for approaching the relatives should be formally trained to ensure a sympathetic and informative approach.

The provision of undergraduate communication skills training in relation to bereavement does not appear to incorporate situation-specific applications such as obtaining consent for autopsies and the process does not continue into postgraduate medical education. ${ }^{3}$ The process of requesting an autopsy from recently bereaved relatives is stressful and any sense of personal discomfort will decrease the motivation of clinicians to request autopsies. ${ }^{4}$ This indifference may be reinforced by unpleasant demonstration facilities, a lack of interest amongst clinical colleagues and hostile relatives who themselves have been influenced by the medical community's failure to appreciate the role of the modern autopsy.

The latter point is supported by the present study in which many of the respondents were found to be unaware of the potential benefits of autopsies. Those clinicians who receive appropriate training may have more confidence and consequently may be more willing to take the time to educate relatives in the nature and the importance of the autopsy.
The manner in which permission for autopsy is sought is important and can influence the decision of the family in approximately one third of cases. ${ }^{5}$ Any significant improvement in autopsy request techniques should stimulate more autopsy requests of a higher standard. Increasing the number and quality of autopsy requests is probably the only basi upon which autopsy rates will ever be improved.

RD START SJ SHERWOOD

University of Sheffield Medical Schoo Beach Hill Road, Sheffield S10 2UL, UK

1 Hinchcliffe SA, Godfrey HW, Hind CRK. Attitudes of junior medical staff to requesting permission for autopsy. Postgrad Med $\mathcal{F} 1994$ 70: $292-4$.

2 Royal College of Pathologists, Royal College of Physicians and the Royal College of Surgeons. Autopsy and audit. A Report of a foint Working Autopsy and audit. $A$

3 Frederikson L, Bull P. An appraisal of the Frederikson $L$, Bull $P$. An appraisal of the in British Medical schools. Soc Sci Med 1992; 34: $515-22$.

4 Sherwood SJ. Motivation to request permission for hospital autopsies: the predictive utility of clinicians' strength of self-efficacy, outcome expectations and outcome values. Thesis (MSc) University of Sheffield.

5 Gardner R, Peskin L, Katz JL. The physician the autopsy request and the consent rate. $7 \mathrm{Med}$ Educ 1973; 48: 636-44.

\section{Clinical presentation of ortho-} static hypotension in the elderly

Sir,

Dr Craig's excellent account of the neurological complications of postural hypotension covered most manifestations of this syndrome. ${ }^{1}$ An additional feature worth mentioning is the presentation with transien focal neurological signs due to co-existing critical stenosis of the carotid or vertebral arteries. ${ }^{2}$ In some of these patients the postural fall in systolic blood pressure may be as little as $10 \mathrm{mmHg}$ (Case 2 in the report by Stark et $a D,{ }^{2}$ this may be sufficient to compromise blood flow through a stenotic internal carotid artery, thereby giving rise to foca weakness on assuming the erect posture. Sometimes transient hemiparesis may be th result of aggravation of postural hypotension by postprandial hypotension, ${ }^{3}$ and this serve as a reminder that clinicians should always ascertain the relationship of focal neurological signs not only to posture but also to meals.

OMP JOLOB

Department of Medicine for the Elderly, Tameside General Hospital, Ashton under Lyne, Lancashire OL6 9RW, UK

Craig GM. Clinical presentation of orthostatic hypotension in the elderly. Postgrad Med $¥ 1994$ 70: $638-42$.

2 Stark RJ, Wodak J. Primary orthostatic cerebral ischemia. $\mathcal{F}$ Neurol Neurosur Psychiatry 1983; 46: 883-91.

3 Kamata T, Yokota T, Furukawa T, et al. Cerebral ischemic attack caused by postprandial hypotension. Stroke 1994; 25: 511-3. 